\title{
FENOMENA DISPARITAS PENGELOLAAN KELAS ANTARA SD NEGERI DAN SWASTA UNGGULAN DI TEGAL
}

\author{
Ulfa Khasanah Yawart ${ }^{1,}$ Ageng Bakti ${ }^{2}$, Resta Rahma Sari ${ }^{3}$ \\ Universitas Negeri Semarang
}

\begin{abstract}
Class management or class management is a conscious effort of a teacher to organize learning activities systematically. Class management is a factor that has the first position as a determinant of student learning outcomes. This study aims to determine the effect of class management between Primary and Private Primary Schools in Tegal. The method used in this study is to use qualitative-quantitative methods. . The object of this study was grade 2 students at the Mendangusuman Public Elementary School (SDK 1) and class 1 SD Pelita Harapan Bangsa (PHB). Data collection techniques in this study used observation, interviews, questionnaires, and documentation techniques. Whereas to analyze the data obtained, researchers used the SPSS version 23.0 statistical program with the results of data analysis stating that the average teacher's ability in classroom management in MKK 1 SDN was 68.52 and in PHB SD was 88.77. While the student learning outcomes in MKK 1 SDN amounted to 94.32 with the lowest score of 86 and the highest score of 100. And for the learning outcomes in elementary school PHB amounted to 98.15 with the lowest score 89 and the highest score of 100.
\end{abstract}

Keyword: Class management, elementary school

\begin{abstract}
Abstrak: Pengelolaan kelas atau manajemen kelas merupakan usaha sadar seorang guru untuk mengatur kegiatan pembelajaran secara sistematis. Pengelolaan kelas merupakan faktor yang mempunyai kedudukan pertama sebagai penentu hasil belajar siswa. penelitian ini bertujuan untuk mengetahui pengaruh pengelolaan kelas antara SD Negeri dan SD Swasta Unggulan di Tegal. Metode yang digunakan dalam penelitian ini adalah dengan menggunakan metode kualitatifkuantitatif. . Objek penelitian ini adalah siswa kelas 2 SD Negeri Mangkukusuman (MKK) 1 dan kelas 1 SD Pelita Harapan Bangsa (PHB). Teknik pengumpulan data dalam penelitian ini menggunakan teknik observasi, wawancara, angket, dan dokumentasi. Sedangkan untuk menganalisis data yang didapat, peneliti menggunakan program statistik SPSS versi 23.0 dengan hasil analisis data menyatakan rata-rata kemampuan guru dalam pengelolaan kelas di SDN MKK 1 adalah 68,52 dan di SD PHB sebesar 88,77. Sedangkan hasil belajar siswa pada SDN MKK 1 sebesar 94,32 dengan nilai terendah 86 dan nilai tertinggi 100. Dan untuk hasil belajar pada SD PHB sebesar 98,15 dengan nilai terendah 89 dan nilai tertinggi 100.
\end{abstract}

Kata Kunci: Pengelolaan kelas, Sekolah dasar

\section{PENDAHULUAN}

Manusia dan pendidikan merupakan suatu hal yang tidak dapat dipisahkan. Sebab pendidikan merupakan kunci dan bekal untuk masa depan manusia. Bahkan pendidikan menjamin perkembangan suatu negara, ini disebabkan karena pendidikan merupakan kunci untuk meningkatkan dan mengembangkan kualitas. Keadaan belajar dalam proses pembelajaran haruslah sesuai dengan rambu-rambu yang telah digariskan, agar tujuan dari pendidikan nasional dapat tercapai. Selain itu, pembelajaran yang menyenangkan dan kondusif merupakan harapan dari semua guru. Namun harapan guru yang menginginkan situasi pembelajaran yang menyenangkan dan kondusif hanya sebatas impian. Sebab guru di era digital ini lebih cenderung memilih yang instan, dan hasilnya adalah pembelajaran yang membosankan.

\footnotetext{
I Pendidikan Guru Sekolah Dasar, Fakultas IImu Pendidikan, Universitas Negeri Semarang, email: khasanah.yawart回gmail.cam

2 Pendidikan Guru Sekolah Dasar, Fakultas Ilmu Pendidikan, Universitas Negeri Semarang, email: agengbakticiut @gmail.com

${ }^{3}$ Pendidikan Guru Sekolah Dasar, Fakultas Ilmu Pendidikan, Universitas Negeri Semarang, email: restarahmasaril997国gmail.com
} 
Pengelolaan kelas atau manajemen kelas merupakan aspek pendidikan yang sering dijadikan perhatian utama oleh para calon guru, guru baru, dan bahkan guru yang telah berpengalaman sekalipun. Alasannya sederhana, yaitu karena calon guru, guru baru, dan guru yang telah berpengalaman berkeinginan agar para peserta didik dapat belajar dengan optimal. Pengelolaan kelas merupakan usaha sadar seorang guru untuk mengatur kegiatan pembelajaran secara sistematis. Pengelolaan kelas yang dilakukan guru dapat mempengaruhi hasil belajar siswa yaitu dengan menggunakan alat peraga sebagai media untuk menyampaikan materi dengan tujuan materi yang disampaikan guru dapat dicerna oleh siswa. Selain itu, cara yang dilakukan guru dalam mencapai hasil belajar siswa adalah dengan menggunakan berbagai metode, model atau pendekatan yang diterapkan dalam setiap pembelajarannya. Dari cara-cara yang dilakukan guru tersebut merupakan salah satu contoh dari pengelolaan kelas.

Majid dalam Umi Setijowati (2016, hlm. 6) menerangkan bahwa pembelajaran merupakan kegiatan terencana yang mengkondisikan/merangsang seseorang agar dapat belajar sesuai dengan tujuan pembelajaran yang diterapkan. Pembelajaran bermuara pada dua kegiatan pokok, yaitu bagaimana cara melakukan tindakan perubahan tingkah laku melalui kegiatan belajar dan bagaimana melakukan tindakan penyampaian ilmu pengetahuan melalui kegiatan mengajar, dan keduanya berlangsung dalam situasi edukatif.

Istilah mengajar menempatkan guru sebagai pemeran utama dalam memberikan informasi, dalam istilah pembelajaran guru lebih banyak berperan sebagai pembimbing dan fasilitator. Menurut Sanjaya dalam Umi (2016, hlm. 7) menjelaskan beberapa karakteristik pembelajaran, antara lain: a) Pembelajaran berarti membelajarkan siswa, b) Proses pembelajaran berlangsung dimana saja, c) Pembelajaran berorientasi pada pencapaian tujuan. Dari ketiga karakteristik ini, peran guru dalam pembelajaran sangatlah besar. Kemampuan guru dalam mengelola kelas haruslah baik sebab dalam pembelajaran bermuara pada penyampaian materi agar tujuan pembelajaran tercapai.

Marzano (2013, hlm. 130-133) menegaskan bahwa pengelolaan kelas berada dalam posisi penting dalam kegiatan guru untuk membelajarkan siswa guna mencapai hasil belajar yang diharapkan. Hal tersebut diperkuat dengan sebuah penelitian yang dilakukan oleh Pingge dan Wangdid (2016), bahwa terdapat hubungan positif kompetensi guru dalam mengelola kelas dengan hasil belajar siswa yang konstribusinya sebesar $24,6 \%$.

Berdasarkan observasi awal yang dilakukan pada 14 April 2018 di SD Negeri Mangkukusuman (MKK) 1 pada kelas 2 dan SD Pelita Harapan Bangsa (PHB) pada kelas 1 diperoleh data primer mengenai karakteristik dari kedua SD, yaitu

Tabel 1. Karakteristik antara SDN MKK 1 dengan SD PHB

\begin{tabular}{|c|c|c|}
\hline Aspek & SDN MKK 1 & SD PHB \\
\hline Siswa & 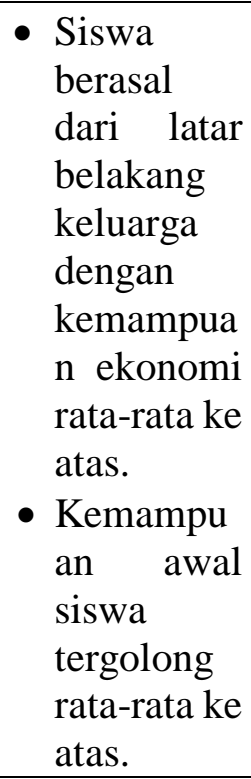 & 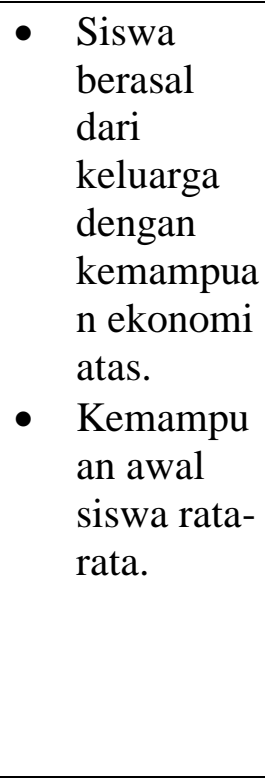 \\
\hline $\begin{array}{c}\text { Pendidi } \\
\text { k }\end{array}$ & $\begin{array}{l}\text { - Guru } \\
\text { sudah } \\
\text { memiliki } \\
\text { jam kerja } \\
\text { tinggi } \\
\text { (sudah } \\
\text { mengajar }\end{array}$ & $\begin{array}{l}\text { - Guru } \\
\text { tergolong } \\
\text { baru dan } \\
\text { muda, } \\
\text { melalui } \\
\text { seleksi } \\
\text { atau tes }\end{array}$ \\
\hline
\end{tabular}




\begin{tabular}{ll}
\hline selama & khusus \\
bertahun- & untuk bisa \\
tahun). & mengajar \\
& di SD. \\
\hline
\end{tabular}

Sumber: Data Primer (Observasi awal peneliti)

Berdasarkan perbedaan-perbedaan

yang terdapat dari masing-masing sekolah dasar terbaik dengan status negeri dan swasta di Kota Tegal, peneliti ingin mengetahui kemampuan guru dalam mencapai keberhasilan pembelajaran. Kemampuan guru yang dikaji dan dianalisis dalam penelitian ini yaitu mengenai guru yang memiliki kemampuan paling baik dalam mengelola kelas, dan hasil belajar siswa dari kedua sekolah dasar tersebut.

\section{METODOLOGI PENELITIAN}

Populasi merupakan wilayah generalisasi yang terdiri atas obyek/subyek yang mempunyai kualitas dan karakteristik tertentu dan ditetapkan oleh peneliti untuk dipelajari dan kemudian ditarik kesimpulannya (Sugiono, 2007). Populasi dari penelitian ini adalah siswa kelas 2 SDN MKK 1 dan siswa kelas 1 SD PHB.

Variabel penelitian adalah segala sesuatu yang berbentuk apa saja dan ditetapkan oleh peneliti untuk dipelajari sehingga diperoleh informasi tentang hal tersebut, kemudian ditarik kesimpulannya (Sugiyono 2017, hlm. 63). Dalam penelitian ini variabel yang digunakan adalah kemampuan guru dalam pengelolaan kelas di SDN MKK 1 dan SD PHB.

Metode penelitian yang digunakan peneliti adalah metode kuantitatifkualitatif. Menurut Creswell dalam Sugiyono (2017, hlm. 404) memberikan definisi tentang metode kualitatifkuantitatif. "Mixed methods research is an approach to inquiry that combines or associated both qualitative guantitative forms of research. It involves philosophical assumptions the use of quantitative and qualitative approaches, and the mixing of both approached in a study". Metode penelitian kuantitatif-kualitatif merupakan pendekatan dalam penelitian yang mengkombinasikan atau menghubungkan antara metode kuantitatif dan kualitatif. Lebih lanjut Creswell menyatakan bahwa, metode ini sering disebut sebagai metode multimethods (menggunakan multi metode), convergence (dua metode bermuara jadi 1), integrated (integrasi dua metode), and combine (kombinasi dua metode).

Teknik pengumpulan data yang digunakan peneliti adalah menggunakan metode observasi, wawancara, angket, dan dokumentasi. Observasi diartikan sebagai pengamatan terhadap pola perilaku manusia dalam situasi tertentu, untuk mendapatkan informasi tentang fenomena yang diinginkan. (Larry Cristensen dalam Sugiyono, 2017, hlm 196). Metode Observasi dilakukan untuk mengamati kemampuan pengeloaan kelas guru saat pembelajaran. Metode wawancara merupakan teknik pengumpulan data dimana pewawancara (peneliti atau yang diberi tugas melakukan pengumpulan data) dalam mengumpulkan data mengajukan suatu pertanyaan kepada yang diwawancarai. (Larry Cristensen dalam Sugiyono, 2017, hlm. 188). Metode wawancara digunakan peneliti guna memperkuat data penelitian setelah melakukan observasi. Menurut Creswell dalam Sugiyono (2017, hlm. 192) menjelaskan bahwa "Questionnaires, are form used in a survey design that participant in a study complete and return to the researcher". Angket merupakan teknik pengumpulan data dimana partisipan/ responden mengisi pertanyaan atau pernyataan kemudian setelah diisi dengan lengkap mengembalikan kepada peneliti. Metode pengumpulan data dengan menggunakan angket digunakan peneliti untuk mengambil data dari responden. Responden yang mengisi angket adalah siswa dan guru. Sedangkan metode dokumentasi digunakan peneliti untuk mendokumentasikan proses pembelajaran dan ruang kelas yang digunakan. 
Data adalah segala fakta dan angka yang dapat dijadikan bahan untuk menyusun suatu informasi (Arikunto 2010, hlm. 161). Data dalam penelitian ini berupa (1) gambar ruang kelas, (2) data angka (persentase) kemampuan guru dalam pengelolaan kelas, (3) video pengelolaan kelas oleh guru, dan (4) data angka hasil belajar siswa. Sumber data adalah subjek dari mana data diperoleh (Arikunto 2010, hlm. 172). Sumber data dalam penelitian ini merupakan kepala sekolah, guru, dan siswa yang terlibat dalam proses pembelajaran di kelas.

Analisis data merupakan kegiatan setelah data dari seluruh responden atau sumber data lain terkumpul. Teknik analisis data yang dilakukan dalam penelitian ini yaitu dengan menggunakan statistik untuk mengetahui skor rat-rata kemampuan guru dalam pengelolaan kelas. Selain itu juga digunakan analisis domain untuk memperoleh gambaran menyeluruh mengenai pengeloaan kelas di SD Negeri Mangkukusuman 1 dan SD Pelita Harapan Bangsa.

\section{HASIL PENELITIAN DAN} PEMBAHASAN

Kemampuan Guru dalam Pengelolaan Kelas 2 di SDN Mangkukusuman (MKK) 1 dan Kelas 1 SD Pelita Harapan Bangsa (PHB)

Hasil analisis berdasarkan data hasil wawancara, observasi, dan angket kemampuan guru dalam pengelolaan kelas dapat dilihat sebagai berikut.

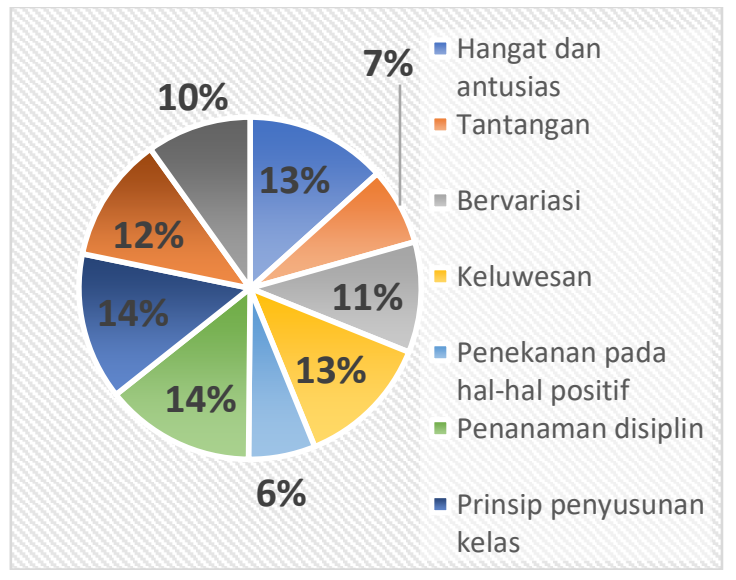

Gambar 1. Pie Chart Kemampuan Guru dalam Pengelolaan Kelas SDN MKK 1

Informasi yang diperoleh dari Gambar 1 adalah bahwa kemampuan guru kelas 2 pada SDN MKK 1 sebesar 44\% atau 68,52. Dari hasil ini kemampuan guru dalam menanamkan disiplin dan prinsip penyusunan kelas lebih besar dibandingkan dengan aspek lainnya. Sedangkan dalam aspek penekanan pada hal-hal positif, guru belum menguasi karena persentase yang didapat sebesar $6 \%$.

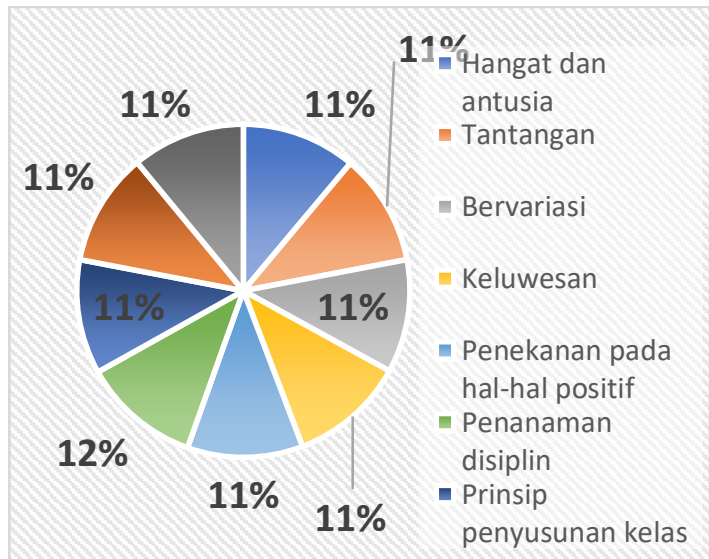

Gambar 2. Pie Chart Kemampuan Guru dalam Pengelolaan Kelas SD PHB

Informasi yang diperoleh dari Gambar 2 adalah bahwa kemampuan guru kelas 1 pada SD PHB sebesar 56\% atau 88,77. Kemampuan guru dalam mengelola kelas pada SD PHB dapat dilihat bahwa pada setiap aspek rata-rata $11 \%$, dan $12 \%$ pada aspek penanaman disiplin.

Dari data di atas, bahwa rata-rata kemampuan guru dalam mengelola kelas memiliki perbedaan. Perbedaan ini dapat disebabkan oleh faktor lain. Berdasarkan perhitungan dengan menggunakan rumus $\mathrm{M}=\frac{\sum \mathrm{x}}{\mathrm{N}}$, diperoleh nilai rata-rata kemampuan guru dalam pengelolaan kelas di SDN MKK 1 yaitu 68,52 atau 44\% dan di SD PHB sebesar 88,77 atau 56\%. 
Hasil Belajar Siswa di SDN Mangkukusuman (MKK) 1 dan SD Pelita Harapan Bangsa (PHB)

Berdasarkan perhitungan dengan menggunakan SPSS hasil belajar siswa di SDN MKK 1 dan PHB dapat dilihat sebagai berikut.

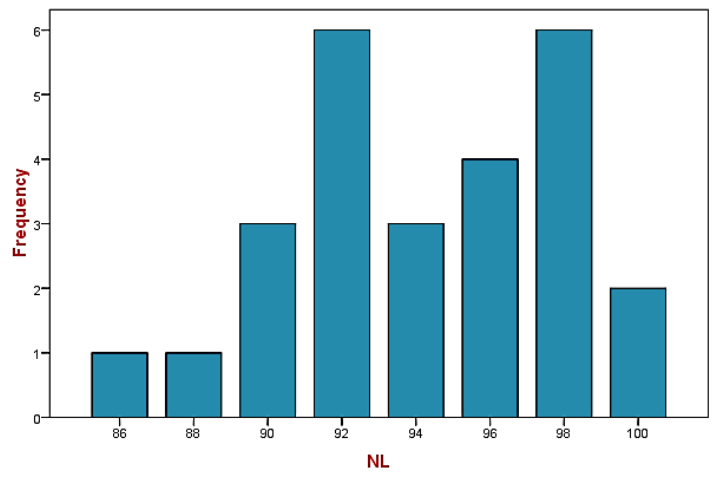

Gambar 3. Hasil Belajar SDN MKK 1

Perhitungan hasil belajar di SDN MKK 1 menunjukkan bahwa rata-rata nilai (mean) hasil belajar siswa sebesar 94,32 dengan nilai terendah 86 dan nilai tertinggi 100 .

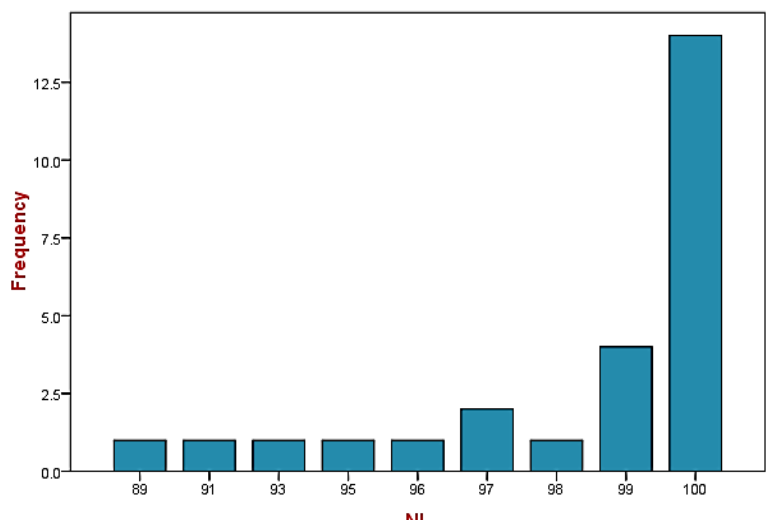

Gambar 4. Hasil Belajar SD PHB

Perhitungan hasil belajar di SD PHB menunjukkan bahwa rata-rata nilai (mean) hasil belajar siswa sebesar 98,15 dengan nilai terendah 89 dan nilai tertinggi 100 .

Dari data di atas diperoleh untuk hasil belajar pada SDN MKK 1 sebesar 94,32. Sedangkan pada SD PHB sebesar 98,15.

\section{KESIMPULAN}

Rata-rata kemampuan guru dalam mengelola kelas berbeda, karena disebabkan oleh beberapa aspek diantaranya adalah prinsip pengelolaan kelas, pendekatan pengelolaan kelas, prosedur dan rancangan pengelolaan kelas, pengaturan kondisi dan penciptaan iklim belajar, dan prinsip disiplin kelas yang digunakan guru. Pada penelitian ini didapat data, bahwa rata-rata kemampuan guru pada SDN MKK 1 sebesar $44 \%$ dan pada SD PHB sebesar 56\%. Dari data tersebut didapat berbagai macam faktor yang mempengaruhi, salah satunya adalah pendidik dan siswa. Pendidik pada SDN MKK 1 merupakan guru yang memiliki jam kerja tinggi (sudah mengajar selama bertahun-tahun) dan pada SD PHB, guru tergolong baru dan muda, melalui seleksi atau tes khusus untuk bisa mengajar di SD. Sedangkan pada aspek siswa di SDN MKK 1 adalah bahwa kemampuan awal siswa tergolong rata-rata ke atas, dan siswa SD PHB memiliki kemampuan awal siswa rata-rata. Dan untuk perbandingan hasil belajar pada SDN MKK 1 sebesar 94,32 dan pada SD PHB sebesar 98,15.

\section{DAFTAR PUSTAKA}

Arikunto, Suharsimi. (2010). Prosedur Penelitian: Suatu Pendekatan Praktik. Jakarata: Rineka Cipta.

Marzano, R.J. (2013). Seni dan Ilmu Pengajaran. Jakarta: PT Indeks.

Setijowati, Umi. (2016). Strategi Pembelajaran SD (Implementasi KTSP dan Kurikulum 2013). Yogyakarta: K-Media

Sugiyono. (2017). Metode Penelitian Kombinasi. Bandung: Alfabeta.

Wangdid, Muhammad Nur. (2016). Faktor yang Mempengaruhi Hasil Belajar Siswa Sekolah Dasar di Kecamatan Kota Tambolaka. Jurnal Pendidikan Sekolah Dasar (Online). Vol. II. No. 1.journal.uny.ac.id (diakses 11 Oktober 2017) 